\title{
Why recommend a brand face-to-face but not on Facebook? How word-of-mouth on online social sites differs from traditional word-of- mouth $^{1}$
}

\author{
Andreas B. Eisingerich* \\ Imperial College
}

HaeEun Helen Chun

Cornell University

Yeyi Liu

Leeds University

He (Michael) Jia

University of Southern California

Simon J. Bell

University of Melbourne

\begin{abstract}
We examine the conceptual difference between consumer electronic word-of-mouth on online social sites (sWOM) such as Facebook and traditional face-to-face word-of-mouth (WOM). We find that consumers are less willing to engage in sWOM than WOM. Such a difference in willingness to offer word-of-mouth can be explained by social risk associated with different communication modes. We show that the difference between people's desire to engage in sWOM and WOM is mediated by perceived social risk and amplified when social risk is made salient. Furthermore, we show that consumers' need to self-enhance mitigates the difference in willingness to offer sWOM versus WOM.
\end{abstract}

Keywords: Word-of-mouth; Social media; Social risk; Self-enhancement need

There are 500 million people on Facebook, but what are they saying to each other? Not much. [ Elmore Leonard]

Introduction

Social online sites such as Facebook are a global phenomenon. Facebook, considered by some as the largest "news" organization in the world (Gans, 2011), has over one billion active users worldwide and over $50 \%$ of all users log on to Facebook on any given day. Recent work (Hennig-Thurau et al., 2010) and conventional wisdom appear to suggest that

\footnotetext{
1 The authors thank the editors Cornelia Pechmann and gratefully acknowledge the constructive guidance and helpful comments of the JCP review team. All authors contributed equally to this article.
}

${ }^{*}$ Corresponding Author 
electronic word-of-mouth on social sites (hereafter referred to as sWOM) such as Facebook is supplanting traditional personal word-of- mouth (hereafter referred to as WOM) as a driver of consumer behavior and that Internet platforms are the "future" of customer relationship management.

While the shift toward e-commerce is undeniable and although both WOM and SWOM have received considerable attention by researchers and theorists of late (Berger \& Schwartz, 2011; Gershoff, Mukherjee, \& Mukhopadhyay, 2003; Schlosser, 2011; Trusov, Bucklin, \& Pauwels, 2009), we still have a limited understanding of how sWOM differs from WOM (Berger \& lyengar, 2013). The distinction matters because consumer choices and decisions are made in the context of relationships consumers have with others (see Simpson, Griskevicius, \& Rothman, 2012 for a recent review). Further, while marketing communications managers are often warned of the "amplification" of consumer voice for the brands they manage (Gillin, 2009), rarely do we consider the implications of this amplification for consumers themselves. In this research, we aim to explore the difference between SWOM and WOM from a perceived risk perspective. The online consumer behavior literature has made regular use of the notion of risk; in particular, focusing on the following three types: (1) financial risk (related to payment security), (2) information risk (related to privacy) (Bart, Shankar, Sultan, \& Urban, 2005), and (3) functional risk (related to uncertainty about product quality and delivery) (Garbarino \& Strahilevitz, 2004). None of these forms of risk, however, fully capture the implications of consumers engaging in sWOM. In contrast, social risk, a type of risk underresearched in the online consumer behavior literature (perhaps due to the remote, nonsocial context of most on-line consumer activities), we suggest, becomes particularly salient in influencing behavior when it comes to word of mouth referral on online social sites.

In three studies we focus on positive word-of-mouth and show that, contrary to conventional wisdom, consumers are less willing to offer sWOM than WOM. We find that the difference in willingness to provide positive sWOM versus WOM is driven by different levels of social risk associated with these two communication modes; while consumers' need to selfenhance reduces the difference in willingness to engage in positive sWOM versus WOM.

\section{Theoretical background}

Word-of-mouth is defined as oral, informal, person-to-person communication between a perceived noncommercial communicator and a receiver regarding a brand, a product, an organization, or a service (Higie, Feick, \& Price, 1987). Interestingly, sWOM (i.e., word-of-mouth on online social sites) shares certain characteristics with WOM (i.e., traditional word-of-mouth) (see Table 1). Unlike WOM, sWOM has the advantage of enabling consumers to share information at a time and place that are most convenient for them (Sun, Youn, Wu, \& Kuntaraporn, 2006), which notionally should make consumers feel more comfortable about sharing their experiences and opinions. However, in contrast to WOM where one-to-one oral communication usually takes place, sWOM is written and broadcast, one-to-many, to an individual's social network. We expect that this key difference between different communication modes leads to a difference between willingness to provide sWOM and WOM.

We draw from social risk and self-enhancement theories to formulate our predictions about consumers' willingness to engage in sWOM compared with WOM. First, we predict that communication mode (i.e., sWOM vs. WOM) influences 
willingness to offer positive word-of-mouth, such that consumers will be less likely to provide sWOM than WOM because of the social risk factors associated with sWOM. Often SWOM is provided within a firmly established, deeply rooted, or everyday-based circle of people, such as family, friends, schoolmates, and acquaintances (Okazaki, 2008; Sun et al., 2006). There is a greater social risk in providing a recommendation to a social network in which one's reputation is built and maintained (Schlenker \& Leary, 1982). Furthermore, compared to WOM, sWOM is communicated to a larger group of people. The presence of a large size of audience to whom the communicator is identifiable also increases the social risk associated with sWOM (Mandel, 2003). Finally, the variable nature of the ties within typical social network platforms (i.e., ranging from close friends to work acquaintances) makes tailoring the message to various audiences nested within the network quite complicated. In contrast, WOM, which typically involves sharing one's view with one or a few others at any given time, allows customization of the message to the audience as well as a natural limit to the responsibility one assumes and the social risk to which one is exposed (Leary, 1990; Leonhardt, Keller, \& Pechmann, 2011). Thus, we predict that the greater social risk associated with sWOM decreases people's willingness to offer sWOM compared to WOM.

While the overall propensity to provide sWOM is less than WOM, this difference is likely to vary given certain contingent conditions. We propose that consumers' need to self-enhance is a critical factor that moderates the effect of communication mode (sWOM vs. WOM) on people's willingness to offer positive word-of-mouth. Self-enhancement refers to people's desire to see themselves in a positive frame and present themselves favorably to others (Baumeister, 1982; Gregg, Hepper, \& Sedikides, 2011; Sedikides \& Gregg, 2008). Prior research suggested that engaging in word-ofmouth activities can be a means to bolster a person's self-concept (Dichter, 1966); there is correlational evidence for the link between self-enhancement and positive word-of-mouth (Hennig-Thurau, Gwinner, Walsh, \& Gremler, 2004). Consumers could even signal their expertise through positive word-of-mouth, thereby maintaining their reputation, bolstering the self-concept, and feeling good about themselves (Wojnicki \& Godes, 2011).

While there is a consensus that self-enhancement need is linked to word-of-mouth activities, the relative impact of self enhancement need on willingness to engage in different modes of word-of-mouth remains unanswered in the literature. We argue that consumers' self-enhancement need is more impactful on willingness to engage in sWOM than WOM, and, as a consequence, it moderates the effect of communication mode on willingness to offer word-of-mouth. The broader reach of social sites such as Facebook means that such platforms will be a particularly effective medium for confirming

Table 1

Comparison between WOM and sWOM.

\begin{tabular}{|c|c|c|}
\hline & WOM & sWOM \\
\hline Receivers & Individuals & Social network \\
\hline Communicators & Identifiable and accountable & Identifiable and accountable \\
\hline Interaction & One-to-one, high level of interaction & One-to-many, moderate level of interaction \\
\hline Communication & $\begin{array}{l}\text { Simultaneous communication through spoken word in a } \\
\text { face-to-face situation }\end{array}$ & $\begin{array}{l}\text { Non-simultaneous communication through written } \\
\text { word in a non-face-to-face situation }\end{array}$ \\
\hline $\begin{array}{l}\text { Social connection between } \\
\text { communicators and receivers }\end{array}$ & Weak or strong ties & Combination of weak and strong ties \\
\hline
\end{tabular}

one's favored brands to others, who are within their own unique personal social network (versus "only one or a few" at a time in WOM), talking about their positive experiences, and receiving feedback on expressed opinions. Relatedly, a recent 
study found that simply browsing online social networks (vs. other online sites) bolsters self-esteem (Wilcox \& Stephen, 2013). We propose that being a message creator and communicating one's positive brand experiences on online social sites represent a greater opportunity for the communicator to self-enhance by potentially influencing the opinions of more than a few people the communicator cares about, which is less easily achieved by traditional WOM.

Consistent with our proposition, recent research also suggested that sWOM allows people to more carefully prepare how they are going to present themselves (Berger \& lyengar, 2013). For these reasons, we expect that people appreciate that sWOM is more effective than is WOM as a way for self-enhancement, and consequently as their need for selfenhancement increases, their willingness to offer sWOM will increase more strongly than will their willingness to offer WOM. Following this logic, we predict that whereas for people with no special need for self-enhancement willingness to engage in SWOM will be lower than in WOM, a high self-enhancement need will reduce the difference in willingness to offer sWOM versus WOM as the need for self-enhancement overrides some of the potential social concerns about sWOM.

Based on these arguments, we make three predictions. First, communication mode has a main effect on word-ofmouth, such that consumers are less likely to provide sWOM than WOM. Second, the difference between willingness to provide sWOM and WOM will be mediated by perceived social risk associated with different communication modes, and this difference will be further magnified when social risk is made salient. Third, consumers' need to self-enhance serves as a boundary condition of the effect of communication mode on word-of-mouth by reducing the gap between willingness to offer sWOM and WOM because the positive impact of self enhancement need on sWOM will be greater than its impact on WOM.

We conducted three experiments to test our predictions. In Study 1, we examined the extent to which consumers' willingness to offer word-of-mouth differs across different communication modes and whether perceived social risk mediates the effect of communication mode (WOM vs. sWOM) on willingness to offer word-of-mouth. In Study 2, we examined how consumers' chronic need for self-enhancement serves as a boundary condition of the effect of communication mode on word-of-mouth. Finally, in Study 3, we replicated the findings of Studies 1 and 2 and provided convergent evidence for the proposed mechanism underlying the relatively lower willingness to offer sWOM by showing the moderating effect of salience of social risk. Study 3 further corroborated the moderating role of need for selfenhancement by priming participants' need for self-enhancement.

\section{Study 1}

\section{Method}

Study 1 ( $\mathrm{N}=118$ ) used a single-factor (communication mode: WOM vs. sWOM) between-subjects design. We asked participants to name one of their favorite brands and then to answer several questions about the brand.

WOM $(a=.90)$ captured willingness to recommend the brand to relatives and friends in person and was measured by adapting the three-item scale of Zeithaml, Berry, and Parasuraman (1996). Items from Zeithaml et al. (1996) were also adapted to measure sWOM; that is, willingness to offer positive word-of-mouth on social sites $(a=.89)$. We created three 
items to measure perceived social risk associated with spreading positive word- of-mouth in either a WOM context (a = $.92)$ or a sWOM context $(a=.98)$. Those three items captured participants' overall perceived social risk and expected disapproval and embarrassment, which are two important components of social risk (Mandel, 2003). Participants' attitude toward their favorite brands was also measured with three items (see Table 2 for the specific items).

\section{Results}

As shown in Fig. 1, participants were more willing to provide

WOM $(M W O M=7.29)$ than $\operatorname{SWOM}(\mathrm{MSWOM}=2.72 ; \mathrm{F}(1,116)=431.16, p<.001)$. Moreover, perceived social risk associated with WOM $\left(\mathrm{M}_{\text {wom }}=3.07\right)$ was lower than that associated with $\operatorname{sWOM}\left(\mathrm{M}_{\mathrm{sWOM}}=6.06 ; \mathrm{F}(1,116)=80.26, p<.001\right)$. A bootstrap-based mediation analysis with 5000 resamples recommended by Preacher and Hayes (2008) further shows that perceived social risk mediated the effect of communication mode on willingness to offer positive word-of-mouth (95\% confidence interval: $-1.54,-.88)$. In addition, brand attitude did not differ across the two conditions $\left(\mathrm{M}_{\text {wom }}=7.23\right.$ versus $\left.\mathrm{M}_{\mathrm{swOM}}=7.34 ; \mathrm{F}(1,116)=.21, p=\mathrm{ns}\right)$, and the results were not affected when brand attitude was added as a covariate.

\section{Discussion}

Study 1 shows that consumers are significantly less willing to say positive things about products on online social sites such as Facebook than in traditional face-to-face settings, even for their favorite brands. Such reluctance to spread positive word-of-mouth on social sites can be explained by the greater perceived social risk associated with sWOM-consumers feel more vulnerable to the judgment of others when broadcasting their opinions to a larger group of recipients of varying degrees of closeness.

Table 2

Study 1: WOM and sWOM measures.

Items

WOM $(1=$ "not at all", $9=$ "very much")

To what extent is it likely that you say positive things about the company to others in person?

To what extent is it likely that you encourage friends and relatives to buy the company's products in person?

To what extent is it likely that you recommend the company to others in person?

$\operatorname{sWOM}(1=$ "not at all", $9=$ "very much")

To what extent is it likely that you say positive things about the company on social sites such as Facebook?

To what extent is it likely that you use social sites to encourage friends and relatives to buy the company's products?

To what extent is it likely that you recommend the company on social sites such as Facebook?

To what extent is it likely that you would become a fan of the company brand pages on social sites such as Facebook?

Perceived social risk in the WOM context ( 1 = "strongly disagree", 9 = "strongly agree")

I feel it is risky to say positive things about the company/products to others in person.

I am worried that people may disapprove of me when I recommend the company/products to them in person.

I am afraid that I may be embarrassed or look stupid by recommending the company/products to friends and relatives in person.

Perceived social risk in the sWOM context $(1=$ "strongly disagree", $9=$ "strongly agree")

I feel it is risky to say positive things about the company/products on social sites such as Facebook.

I am worried that people may disapprove of me when I recommend the company/products on social sites such as Facebook.

I am afraid that I may be embarrassed or look stupid by recommending the company/products on social sites such as Facebook. 


\section{Study 2}
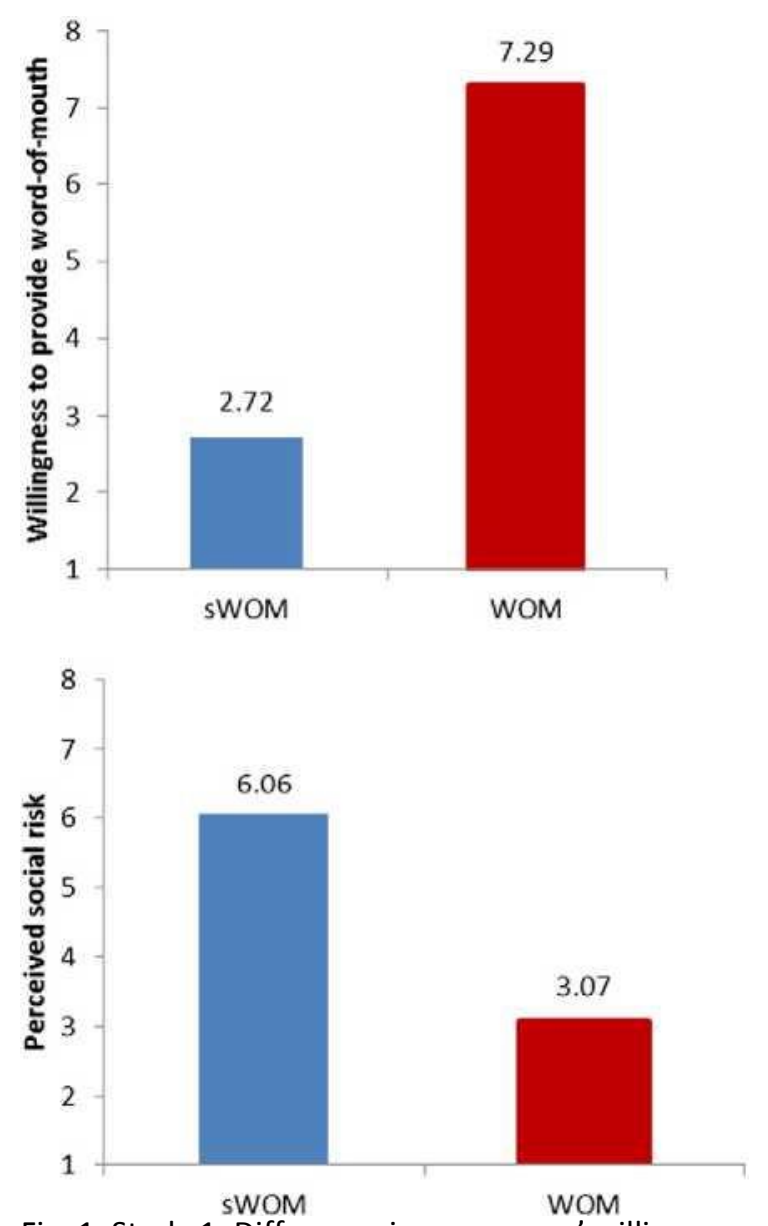

Fig. 1. Study 1: Difference in consumers' willingness to offer sWOM versus WOM. Study 1: Difference in perceived social risk associated with sWOM versus WOM.
The purpose of Study 2 was to examine a potential boundary condition of the main effects identified in Study 1 . Specifically, we investigated the moderating role of one's need for selfenhancement on the main effect of communication channel on word-of-mouth referral.

\section{Method}

We collected data from Starbucks customers, who were approached as they walked out of the shop and asked if they were willing to take part in a research study. Over the course of eight days we received a total of 208 usable responses. In Study 2, communication mode was manipulated within-subjects, and WOM $(a=.92)$ and $\operatorname{sWOM}(a=.98)$ were measured identically to Study 1, except for using Starbucks as the focal brand. Consumers' need for self-enhancement was measured by Gregg et al.'s (2011) two-item scale: “In general, I like to hear that I am a great person" and "In general, I want to discover that I have excellent qualities" (1 = "strongly disagree", 9 = "strongly agree"; $r=.84)$.

\section{Results}

We followed the procedure proposed by Judd, Kenny, and McClelland (2001) and Spiller, Fitzsimons, Lynch, and McClelland (2013) to test a moderated regression model in which the independent variable (i.e., communication mode) is a withinsubjects factor and the moderator (i.e., self-enhancement need) is a continuous variable. We created a contrast score for each respondent by subtracting the score of willingness to provide sWOM from the score of willingness to provide WOM $\left(Z_{\text {contrast }}=Z_{\text {wom }}-Z_{\text {swom }}\right)$, and then regressed the contrast score on self-enhancement need. We mean centered the score of self enhancement need so that in the regression model the intercept (i.e., the constant term) equals the main effect of communication mode, and the regression coefficient of self-enhancement need represents its moderating effect (Judd et al., 2001).

The regression analysis generated a significant main effect of communication mode $(c=.63, t=5.06, p<.001)$, replicating the findings of Study 1 that people are less willing to offer sWOM than WOM. More importantly, the regression coefficient of self-enhancement need was also significant $(b=-.51, t=-8.82, p<.001)$, indicating that self-enhancement need moderated the difference between willingness to provide SWOM and WOM.

To better understand this interaction, we conducted a spotlight analysis, in which we created new independent variables by subtracting either the value of one standard deviation below the mean or the value of one standard deviation 
above the mean from the self-enhancement need score respectively, such that the intercept of the regression line equals the simple effect of communication mode at one standard deviation below or above the mean of self-enhancement need (Spiller et al., 2013). When self-enhancement need was low (i.e., one standard deviation below the mean), willingness to offer sWOM was lower than WOM (M $\mathrm{S}_{\mathrm{s}}$ WOM $=1.26 \mathrm{vs}$. MWOM $\left.=2.99 ; \mathrm{c}=1.73, \mathrm{t}=9.82, p<.001\right)$. In contrast, when selfenhancement need was high (i.e., one standard deviation above the mean), the effect of communication mode was not only mitigated, but also even reversed, such that participants were more willing to provide sWOM than WOM (Mswom $=$ 4.82 vs. $\mathrm{M}_{\text {wom }}=4.35 ; \mathrm{c}=-.47, \mathrm{t}=-2.67, p<.01$ ) (see Fig. 2 ).

\section{Discussion}

The findings of Study 2 show that willingness to offer sWOM is significantly lower than willingness to offer WOM for those consumers who do not have a high, chronic need to self-enhance, replicating the findings of Study 1 . However, this pattern is mitigated, and surprisingly reversed, for consumers who have a chronic need for self-enhancement, such that their willingness to offer sWOM exceeds their willingness to offer WOM. We further tested the moderating role of selfenhancement need in Study 3 by employing a manipulation approach rather than relying on a self-reported individual difference measure. Study 3 also aimed to lend further support for the role of social risk as an underlying driver for the difference between sWOM and WOM by manipulating salience of social risk and showing that salience of social risk further amplifies such a difference.

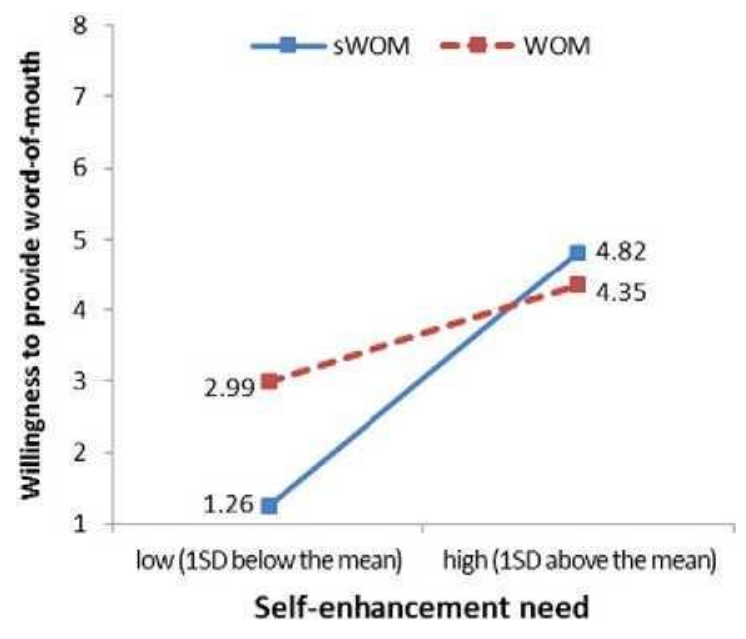

Fig.2. Study 2: Interaction between communication mode and self-enhancement need.

\section{Study 3}

\section{Method}

Study 3 used a 2 (communication mode: WOM vs. sWOM) x (self-enhancement need: high vs. control) $\times 2$ (salience of social risk: high vs. control) mixed experimental design, with the first factor manipulated within-subjects and the latter two factors manipulated between-subjects. The study was conducted in two parts, with 161 postgraduate students voluntarily taking part in the study as part of a regular course. 
Participants were randomly assigned to one of the noted four conditions. In the first part, we manipulated a need for self enhancement through episodic priming, following De Angelis, Bonezzi, Peluso, Rucker, and Costabile (2012). Participants in the high self-enhancement need condition were asked to think about the poorest performance during their academic career and describe their experience in detail. Reminding people of their poorest performance in the past was shown to activate a strong need to self-enhance because in such a circumstance people are motivated to restore a positive self-view (De Angelis et al., 2012). Participants in the control condition were asked to think about their last trip to the grocery store and write about their experience in detail. Next, participants in the high social risk salience condition were given a text ostensibly from Psychology Today (see Appendix A) about the possibility of people being judged by what they say and share with others. Participants in the control condition received no text and moved directly to answering the second part of our study.

In the second part, participants were asked to think of and write down their favorite brand and answer all subsequent questions with their favorite brand in mind. WOM $(a=.99)$ and SWOM $(a=.99)$ were measured similarly to Study 1 (see Table 3

Study 3: WOM, sWOM, and Facebook-related measures.

Items

WOM $(1=$ "not at all", $9=$ "very much")

To what extent is it likely that you say positive things about the company to others in person?

To what extent is it likely that you encourage friends and relatives to buy the company's products in person?

To what extent is it likely that you recommend the company to others in person?

sWOM $(1=$ "not at all", $9=$ "very much")

To what extent is it likely that you say positive things about the company on social sites such as Facebook?

To what extent is it likely that you use social sites to encourage friends and relatives to buy the company's products?

To what extent is it likely that you recommend the company on social sites such as Facebook?

To what extent is it likely that you would become a fan of the company brand pages on social sites such as Facebook?

Brand attitude

To what extent do you view the company as ( -5 = "dislike", "bad", "negative", 5 = "like", "good", "positive")?

Brand experience

My prior experience with the company has primarily been ( 1 = "negative", 9 = "positive").

Ease-of-use of Facebook ( 1 = "strongly disagree", 9 = "strongly agree")

It is easy to become skillful at using Facebook.

Learning to use Facebook is/was easy for me.

In general, I find Facebook easy to use.

It is easy to get Facebook to do what I want it to do.

Interest in Facebook ( 1 = "strongly disagree", 9 = "strongly agree")

Facebook is very important to me.

Facebook is relevant to me.

Facebook matters a lot to me.

I have a strong interest in Facebook.

Frequency of use of Facebook ( 1 = "strongly disagree", 9 = "strongly agree")

I log on to Facebook every day.

I spend long periods of my time on Facebook.

I am an active user of Facebook.

Appropriateness of Facebook for personal brand endorsements

Please indicate the extent to which you agree that it is appropriate to use social media such as Facebook to express personal endorsement of a brand

(1 = "strongly disagree", 9 = "strongly agree").

PANAS ( 1 = "very slightly or not at all", $3=$ "a little", $5=$ "moderately", 7 = "quite a bit", $9=$ "extremely")

This scale consists of a number of words that describe different feelings. Indicate the extent to which you feel this way right now.

Positive affect: "interested", "excited", "strong", "enthusiastic", "proud", "inspired", "determined", "alert", "attentive", "active",

Negative affect: "distressed", "upset", "guilty", "scared", "hostile", "irritable", "ashamed", "nervous", "jittery", "afraid". 
Table 3). Participants answered the same need for self enhancement measure as in Study $2(r=.95)$. As a manipulation check for salience of social risk, participants answered the following two-item measure ("Other people are likely to form impressions of me based on my shared opinions", "Other people are likely to evaluate my expressed opinions"; 1 = "strongly disagree", 9 = "strongly agree"; $r=.96)$.

As part of our analyses we accounted for a battery of control variables (brand attitude, prior experience, interest in Facebook, ease-of-use, frequency of usage, appropriateness of social media to express personal endorsements of a brand, participants' feelings using Watson, Clark, and Tellegen's (1988) positive and negative affect schedule (PANAS), and their number of friends on Facebook) as detailed in Table 3.

\section{Results}

\section{Manipulation and confound checks}

A set of 2 (self-enhancement need: high vs. control) $\times 2$ (salience of social risk: high vs. control) ANOVAs on the manipulation checks revealed that the manipulations worked as expected (see Table 4). Specifically, participants in the high (vs. control) self-enhancement condition noted higher needs for self-enhancement (Mhigh = 6.45 vs. Mcontrol = 3.72; $F(1,157)=92.75, p<.001$ ). Participants in the high (vs. control) social risk salience condition noted higher levels of perceived social risk (Mhigh $=6.38$ vs. Mcontrol $=3.96 ; F(1,157)=66.29, p<.001)$. No other effects were observed for these variables. An additional set of ANOVAs indicated that the conditions did not differ in ways that might produce potential confounds, except for that participants in the control condition reported a more positive affect than those in the high need for self-enhancement condition (Mhigh $=3.79$ vs. Mcontrol $=4.37 ; F(1,157)=5.95, p<.05)$ (see Table 4). Nevertheless, using positive affect and other control variables as covariates in the mixed ANOVA model did not change our results. For the purpose of parsimony, in the next section we only reported the results based on the model without

Table 4

Study 3: Manipulation checks and testing of predictions.

\begin{tabular}{|c|c|c|c|c|}
\hline Means & $\begin{array}{l}\text { High self-enhancement/high } \\
\text { social risk }(N=40)\end{array}$ & $\begin{array}{l}\text { Control/high } \\
\text { social risk }(N=43)\end{array}$ & High self-enhancement/control $(N=39)$ & Control/control $(N=39)$ \\
\hline \multicolumn{5}{|l|}{ Manipulation checks } \\
\hline Self-enhancement need & $6.56^{\mathrm{a}}$ & $3.94^{\mathrm{b}}$ & $6.33^{\mathrm{a}}$ & $3.50^{b}$ \\
\hline Social-risk salience & $6.50^{\mathrm{a}}$ & $6.26^{\mathrm{a}}$ & $4.03^{\mathrm{b}}$ & $3.90^{b}$ \\
\hline \multicolumn{5}{|l|}{ Confound checks } \\
\hline Brand attitude & $3.91^{\mathrm{a}}$ & $3.95^{\mathrm{a}}$ & $3.80^{\mathrm{a}}$ & $3.82^{\mathrm{a}}$ \\
\hline Brand experience & $6.35^{a}$ & $6.72^{\mathrm{a}}$ & $6.69^{\mathrm{a}}$ & $6.26^{4}$ \\
\hline Ease-of-use of Facebook & $6.03^{\mathrm{a}}$ & $6.17^{\mathrm{a}}$ & $6.64^{\mathrm{a}}$ & $6.68^{\mathrm{a}}$ \\
\hline Interest in Facebook & $3.63^{\mathrm{a}}$ & $3.87^{\mathrm{a}}$ & $3.17^{\mathrm{a}}$ & $3.93^{\mathrm{a}}$ \\
\hline Frequency of use of Facebook & $3.83^{\mathrm{a}}$ & $4.32^{\mathrm{a}}$ & $3.99^{\mathrm{a}}$ & $4.03^{a}$ \\
\hline $\begin{array}{l}\text { Appropriateness of Facebook for } \\
\text { personal brand endorsements }\end{array}$ & $4.80^{\mathrm{a}}$ & $5.05^{\mathrm{a}}$ & $4.44^{\mathrm{a}}$ & $4.82^{2}$ \\
\hline Positive affect & $3.76^{\mathrm{a}}$ & $4.65^{\mathrm{b}}$ & $3.82^{\mathrm{a}}$ & $4 \cdot 10^{\mathrm{a}, \mathrm{b}}$ \\
\hline Negative affect & $4.25^{\mathrm{a}}$ & $4.39^{a}$ & $4.39^{a}$ & $4.19^{a}$ \\
\hline Number of friends on Facebook & $4.98^{2}$ & $5.05^{\mathrm{a}}$ & $4.87^{\mathrm{a}}$ & $5.05^{2}$ \\
\hline Gender & $1.30^{\mathrm{a}}$ & $1.49^{\mathrm{a}}$ & $1.39^{\mathrm{a}}$ & $1.49^{a}$ \\
\hline \multicolumn{5}{|l|}{ Dependent variables } \\
\hline sWOM & $4.70^{b}$ & $4.06^{b}$ & $6.41^{\mathrm{a}}$ & $3.87^{b}$ \\
\hline WOM & $6.36^{\mathrm{a}}$ & $6.58^{\mathrm{a}}$ & $6.20^{\mathrm{ab}}$ & $5.36^{\mathrm{b}}$ \\
\hline
\end{tabular}

Means with different subscripts are significantly different, $p<.05$. 
those covariates included.

\section{Self-enhancement need, salience of social risk, and sWOM versus WOM}

Our results revealed a main effect of communication mode (MWOM $=6.14 \mathrm{vs.} \mathrm{MsWOM}=4.74 ; \mathrm{F}(1,157)=32.85, p<.001)$. The greater willingness to offer WOM versus sWOM replicated our findings of Studies 1 and 2. Moreover, the selfenhancement need $x$ social risk salience $x$ communication mode three-way interaction was not significant $(F(1,157)=.80$, $p=n s)$, enabling us to explore the self-enhancement need $x$ communication mode interaction and the social risk salience $x$ communication mode interaction separately.

Central to our predictions, the interactions between communication mode and self-enhancement need $(F(1,157)=$ $7.20, p<.01)$ and between communication mode and salience of social risk $(F(1,157)=9.34, p<.01)$ were both significant. First, the interaction between communication mode and self enhancement need replicated the findings of Study 2 such that a high self-enhancement need mitigated the difference between willingness to offer sWOM and WOM. Specifically, whereas sWOM was significantly lower than WOM in the control condition (MwOM $=5.97$ vs. MswoM $=3.97 ; F(1,157)=36.04,<.001)$, the difference between sWOM and WOM, although still significant, was greatly reduced in the high-selfenhancement need condition $\left(M_{\text {wom }}=6.28\right.$ vs. $\left.M_{s w o m}=5.55 ; F(1,157)=4.57, p<.05\right)$ (see Fig. 3). These results further establish the need for self-enhancement as a boundary condition for the effect of communication mode on wordof-mouth.

Second, we explored the interaction between communication mode and salience of social risk. We found that whereas participants were marginally less willing to offer $\operatorname{WWOM}$ than WOM (MWOM $=5.78$ vs. $\operatorname{MswOM}=5.14 ; F(1,157)=$

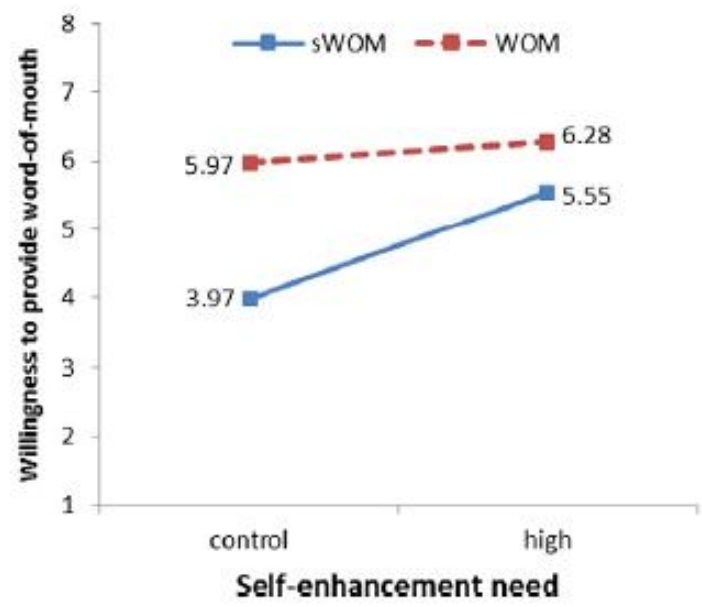

Fig. 3. Study 3: Interaction between communication mode and self-enhancement need.

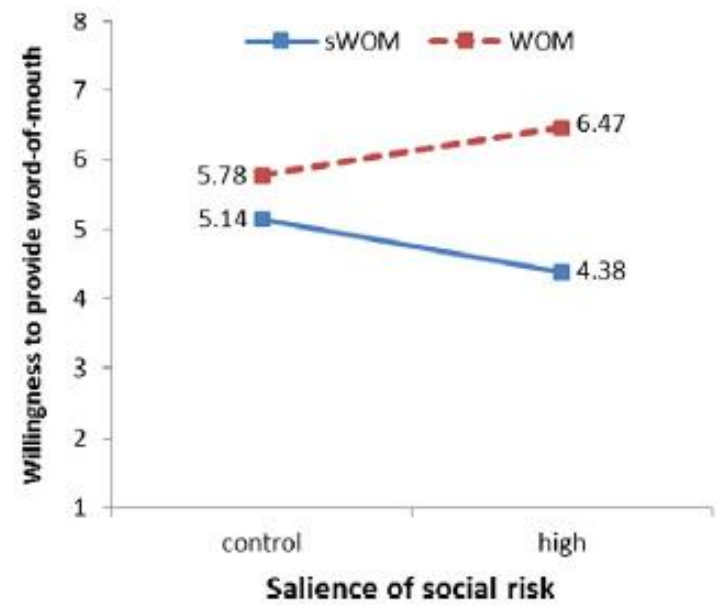

Fig. 4. Study 3: Interaction between communication mode and salience of social risk.

$3.47, p=.06$ ) in the control condition, this difference was significantly amplified (MWOM $=6.47 \mathrm{vs} . \mathrm{M}_{\mathrm{s}} \mathrm{WOM}=4.38 ; \mathrm{F}(1,157)$ $=39.83, p<.001$ ) when social risk was made highly salient (see Fig. 4). These results lend convergent support for the role of social risk in driving a relatively lower willingness to offer sWOM versus WOM. 


\section{Discussion}

Study 3 independently manipulated the need to self-enhance and salience of social risk to examine their roles in moderating the difference between consumers' willingness to engage in sWOM and WOM. Overall, the findings that consumers are less willing to engage in sWOM versus WOM replicated those of Studies 1 and 2. As was the case in Study 2 , self-enhancement need in Study 3 was also found to mitigate the relatively lower willingness to offer sWOM versus WOM. It is encouraging that the results were consistent regardless of whether self-enhancement was measured as an individual difference variable or manipulated. More importantly, the results of this study show that the relatively lower willingness to offer sWOM versus WOM is further amplified when social risk is made salient and further support perceived social risk as a critical driver of the difference between people's willingness to offer sWOM and WOM.

\section{General discussion and implications}

We find that consumers are generally less likely to offer SWOM than traditional WOM. This difference is a function of perceived social risk associated with different communication modes. Supporting our theorization, perceived social risk mediates the effect of communication mode (WOM vs. sWOM) on people's willingness to provide word-of-mouth in Study 1 , and salience of social risk further magnifies the difference between people's desire to offer sWOM and WOM in Study 3. Furthermore, we find that self-enhancement need mitigates the difference between consumers' willingness to provide sWOM and WOM, regardless of whether they inherently possess a high self-enhancement need as in Study 2 or when their self-enhancement need is temporarily evoked as in Study 3.

The findings contribute to the literature by demonstrating the key conceptual differences between sWOM and WOM; that is, sWOM is more sensitive to self-enhancement motives and to social risk perceptions than WOM. These findings are also of particular relevance for marketing practice. Heightening consumers' need to self-enhance can encourage word of mouth referral in the firm's favor. Further, marketers should take steps to ensure that consumers do not feel threatened by social judgments and sanctions as a result of sWOM. Perhaps providing opportunities for consumers to selectively share their opinions with members of their social network (e.g., Google Circles) might help achieve this. Our research can be extended to several interesting areas for future research. Although our research looked solely at positive word-of-mouth and brand endorsement, it is worthwhile to further explore negative sWOM versus WOM and test to what extent the current findings can be generalized to a negative word-of-mouth context, for instance, when consumers become averse to a brand (Park, Eisingerich, \& Park, 2013). Firms' attempting to reduce consumers' perception of social risk and increase their need for self-enhancement in order to benefit from the upside of greater positive word-of-mouth referral, face a larger downside should a study of negative word-of-mouth reveal similar results.

\section{Appendix A. Study 3 social risk manipulation stimulus}

Before moving to the second study, we would like you to read the following excerpt from Psychology Today, which disseminates research findings from the field of Behavioral Science. 


\section{References}

Bart, Y., Shankar, V., Sultan, F., \& Urban, G. L. (2005). Are the drivers and role of online trust the same for all web sites and consumers? A large-scale exploratory empirical study. Journal of Marketing, 69, 133-152.

Baumeister, R. F. (1982). A self-presentational view of social phenomena.

Psychological Bulletin, 1, 3-26.

Berger, J., \& lyengar, R. (2013). Communication channels and word of mouth: How the medium shapes the message. Journal of Consumer Research, 40, 567-579.

Berger, J., \& Schwartz, E. M. (2011). What drives immediate and ongoingword of mouth? Journal of Marketing Research, $\underline{38,869-880 .}$

De Angelis, M., Bonezzi, A. Peluso, A. M., Rucker, D. D., \& Costabile, M. (2012). On braggarts and gossips: A selfenhancement account of word-of-mouth generation and transmission. Journal of Marketing Research, 49, 551-563.

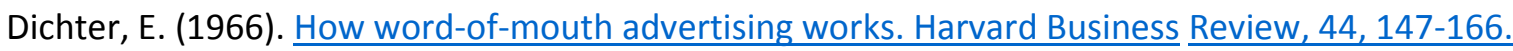

Gans, J. (2011). Facebook is the largest news organization ever. Retrieved March 14,2011 from. http://blogs.hbr.org/cs/2011/03/facebook is the larges1L news o.html

Garbarino, E., \& Strahilevitz, M. (2004). Gender differences in the perceived risk of buying online and the effects of receiving a site recommendation. Journal of Business Research, 57, 768-775.

Gershoff, A., Mukherjee, A., \& Mukhopadhyay, A. (2003). Consumer acceptance of online agent advice: Extremity and positivity effects. Journal ofConsumer Psychology, 13, 161-170.

Gillin, P. (2009). The new influencers: A marketer's guide to the new social media. Linden Publishing.

Gregg, A. P., Hepper, E. G., \& Sedikides, C. (2011). Quantifying self-motives: Functional links between dispositional desires. European Journal of Social Psychology, 41, 840-852.

Hennig-Thurau, T., Gwinner, K. P., Walsh, G., \& Gremler, D. D. (2004). Electronic word-of-mouth via consumer-opinion platforms: What motivates consumers to articulate themselves on the internet? Journal of Interactive Marketing, 18, 38-52.

Hennig-Thurau, T., Malthouse, E. C., Friege, C., Gensler, S., Lobschat, L., Rangaswamy, A., et al. (2010). The impact of new media on customer relationships. Journal of Service Research, 13, 311-330.

Higie, R. A., Feick, L. F., \& Price, L. L. (1987). Types and amount of word-of- mouth communications about retailers. Journal of Retailing, 63, 260-278.

Judd, C. M., Kenny, D. A., \& McClelland, G. H. (2001). Estimating and testing mediation and moderation in within-subject designs. Psychological Methods, 6, 115-134.

Leary, M. R. (1990). Responses to social exclusion: Social anxiety, jealousy, loneliness, depression, and low self-esteem. Journal ofSocial and Clinical Psychology, 9, 221-229.

Leonhardt, J. M., Keller, L. R., \& Pechmann, C. (2011). Avoiding the risk of responsibility by seeking uncertainty: $\underline{\text { Responsibility aversion and preference for indirect agency when choosing for others. Journal of Consumer Psychology, }}$ 21, 405-413.

Mandel, N. (2003). Shifting selves and decision making: The effects of self- construal priming on consumer risk-taking. Journal ofConsumer Research, 30, 30-40.

Okazaki, S. (2008). Determinant factors of mobile-based word-of-mouth campaign referral among Japanese adolescents. Psychology and Marketing, 25, 714-731.

Park, C. W., Eisingerich, A. B., \& Park, J. W. (2013). Attachment-aversion (AA) model of customer-brand relationships. Journal of Consumer Psychology, 23, 229-248.

Preacher, K. J., \& Hayes, A. F. (2008). Asymptotic and resampling strategies for assessing and comparing indirect effects in multiple mediator models. Behavior Research Methods, 40, 879-891. 
Schlenker, B. R., \& Leary, M. R. (1982). Social anxiety and self-presentation: A conceptualization model. Psychological Bulletin, 92, 641-669.

Schlosser, A. E. (2011). Can including pros and cons increase the helpfulness and persuasiveness of online reviews? The interactive effects of ratings and arguments. Journal of Consumer Psychology, 21, 226-239.

Sedikides, C., \& Gregg, A. P. (2008). Self-enhancement: Food for thought. Perspectives on Psychological Science, 3, 102116.

Simpson, J. A., Griskevicius, V., \& Rothman, A. J. (2012). Consumer decisions in relationships. Journal of Consumer Psychology, 22, 304-315.

Spiller, S. A., Fitzsimons, G. J., Lynch, J. G., Jr., \& McClelland, G. H. (2013). Spotlights, floodlights, and the magic number zero: Simple effects tests in moderated regression. Journal of Marketing Research, 50, 277-288.

Sun, T., Youn, S., Wu, G., \& Kuntaraporn, M. (2006). Online word-of-mouth (or mouse): An exploration of its antecedents and consequences. Journal of Computer-Mediated Communication, 11, 1104-1127.

Trusov, M., Bucklin, R. E., \& Pauwels, K. (2009). Effects of word-of-mouth versus traditional marketing: Findings from an internet social networking site. Journal of Marketing, 73, 90-102.

Watson, D., Clark, L. A., \& Tellegen, A. (1988). Development and validation of brief measures of positive and negative affect: The PANAS scales. Journal of Personality and Social Psychology, 54, 1063-1070.

Wilcox, K., \& Stephen, A. T. (2013). Are close friends the enemy? Online social networks, self-esteem, and self-control. Journal ofConsumer Research, 40, 90-103.

Wojnicki, A. D., \& Godes, D. (2011). Signaling success: Strategically- positive word ofmouth. Working paper. University of Maryland, College Park.

Zeithaml, V. A., Berry, L. L., \& Parasuraman, A. (1996). The behavioral consequences of service quality. Journal of Marketing, 60, 31-46. 